Review Article

\title{
Indirubin and Indirubin Derivatives for Counteracting Proliferative Diseases
}

\author{
Tina Blažević, ${ }^{1}$ Elke H. Heiss, ${ }^{1}$ Atanas G. Atanasov, ${ }^{1}$ Johannes M. Breuss, ${ }^{2}$ \\ Verena M. Dirsch, ${ }^{1}$ and Pavel Uhrin ${ }^{2}$ \\ ${ }^{1}$ Department of Pharmacognosy, University of Vienna, 1090 Vienna, Austria \\ ${ }^{2}$ Department of Vascular Biology and Thrombosis Research, Center for Physiology and Pharmacology, Medical University of Vienna, \\ 1090 Vienna, Austria
}

Correspondence should be addressed to Pavel Uhrin; pavel.uhrin@meduniwien.ac.at

Received 3 June 2015; Revised 23 August 2015; Accepted 24 August 2015

Academic Editor: Isabel Andújar

Copyright (C) 2015 Tina Blažević et al. This is an open access article distributed under the Creative Commons Attribution License, which permits unrestricted use, distribution, and reproduction in any medium, provided the original work is properly cited.

Indirubin is the active component of Danggui Longhui Wan, a traditional Chinese medicine formulation. The encouraging clinical results from the 1980s obtained in chronic myelocytic leukemia patients treated with indirubin stimulated numerous studies on this compound. These investigations explored the use of indirubin in different types of cancer and reported the synthesis of novel derivatives with improved chemical and pharmacokinetic properties. In this paper, we review the impressive progress that has been made in elucidating the mechanistic understanding of how indirubin and its derivatives affect physiological and pathophysiological processes, mainly by inhibition of cell proliferation and induction of cell death. Furthermore, we survey the therapeutic use of these compounds in combating proliferative diseases such as cancer, restenosis, and psoriasis.

\section{Introduction}

Historically, natural products have been successfully used in the management of a large number of human diseases [1]. Natural products may also serve as a basis for synthesis of derivatives aiming to reduce toxic side effects, to improve their pharmacokinetic properties, and to increase their efficacy [1-3]. The molecular targets and mechanisms of these substances in physiology or pathophysiology have been elucidated only in the last decades.

Indirubin is the active ingredient of Danggui Longhui Wan, a traditional Chinese medicine containing plants such as Indigofera tinctoria L. and Isatis tinctoria L. The interest in clinical use of indirubin was evoked in the 1980s in China when medical doctors together with scientists started testing its clinical use for treatment of chronic myelocytic leukemia (CML), a slowly progressive disease characterized by the overproduction of granulocytes [4-7]. Over 50\% of the treated CML patients exhibited partial or complete remission $[6,8,9]$, similar to the standard treatment using the cytostatic agent busulfan [8]. Indirubin toxicity was low and the side effects experienced by about half of the participants comprised mild abdominal pain, diarrhea, and nausea [7]. In three cases reversible pulmonary arterial hypertension and cardiac insufficiency were reported [10].

These encouraging results with CML stimulated researchers to explore the use of indirubin and its novel derivatives in other types of cancer as well as other diseases [11-14]. Here, we survey the outcome of these studies in combating proliferative diseases, such as cancer, pathological angiogenesis, restenosis, and psoriasis, and discuss the underlining mechanisms regarding how indirubin influences cellular signaling. In the text, we refer to natural indirubin as well as its chemical derivatives as indirubins.

\section{Synthetic Indirubin Derivatives}

Indirubin, a stable red isomer of the blue indigo, is chemically a $3,2^{\prime}$-bisindole. In many laboratories the structure of indirubin was employed as a skeleton for the synthesis of new derivatives, with improved chemical and pharmacological properties such as solubility and absorption. The antiproliferative effects of indirubins were mostly attributed 
to the inhibition of cell cycle-related kinases, like cyclindependent kinases (CDKs) and glycogen synthase kinase- $3 \beta$ $($ GSK-3 $\beta)$, and later on to other target proteins, as described further in the text. New indirubin derivatives, in addition to increased antiproliferative properties, served as important tools in revealing specific targets that mediate their cellular effects.

The first classes of synthesized indirubin-based compounds included alkylated, halogenated, and $\mathrm{N}$ - and $\mathrm{O}$-substituted derivatives. Among these, N-ethyl-indirubin, 5-halogen-indirubins, and N-methylisoindigotin (meisoindigo) demonstrated much higher antitumor potency in animal models than natural indirubin [15-17]. Indirubin$3^{\prime}$-monoxime (a substance with numerous synonyms such as indirubin- $3^{\prime}$-oxime, indirubin-3-oxime, indirubin-3monoxime, indirubinoxime, and indirubin- $3^{\prime}$-monoxime) was synthesized in 1996 by $\mathrm{Li}$ and colleagues [18] and was later found to inhibit CDKs, a major target of indirubins, with higher potency when compared to the parent compound [9]. To date, indirubin- $3^{\prime}$-monoxime has become one of the most studied synthetic indirubin derivatives. This substance similar to some other newly synthesized indirubins (5iodoindirubin- $3^{\prime}$-monoxime, indirubin-5-sulfonic acid, indirubin-5-sulfonamide, and 5-halogenoindirubins) inhibits efficiently, at nanomolar range, another indirubin target, the GSK-3 $\beta$ [19]. Next, using cocrystal structures and modeling approaches, novel and more potent CDK and GSK-3 $\beta$ inhibitors such as 6-bromoindirubin were discovered [33]. Thereafter, 6-bromoindirubin-3'-oxime having higher potency towards GSK-3 $\beta$ was developed [20]. Additionally, novel $3^{\prime}$-substituted 7-halogenoindirubins lacking the inhibitory effects towards CDKs and GSK$3 \beta$ were generated, which nevertheless still induced cell death in a diversity of human tumor cell lines [21]. This allowed researchers to point to the importance of other mechanisms mediating indirubin effects [21]. The synthesis and characterization of several other derivatives, such as E564, E728, and E804, demonstrated the inhibitory effect of these compounds towards signal transducers and activators of transcription 3 (STAT3) signaling, thereby contributing to the induction of apoptosis in human cancer cells [22]. STATs are transcription factors that transmit signals from membrane receptors to the nucleus, where they promote the transcription of their target genes or play an important role in regulating cell cycle progression and in apoptosis [34, 35].

The study on the novel indirubin derivatives 5-nitroindirubinoxime, 5-fluoro-indirubinoxime, and 5-trimethylacetamino-indirubinoxime (originally [23] denoted incorrectly as substituted at the five-prime position on the indirubin molecule) demonstrated their antitumor activity in vitro and in several animal models for cancer [2327], while 5-nitro-indirubinoxime additionally exhibited anti-inflammatory properties in human vascular endothelial cells [28]. In comparison with other known indirubins, 7-azaindirubin bearing a heterocyclic nitrogen atom at position $\mathrm{C} 7$ as well as its $3^{\prime}$-oxime derivative shows reduced kinase inhibitory activity but nevertheless demonstrates high antiproliferative activity [29]. Newly synthesized (di)azaindirubins exhibit a highly selective inhibitory activity against casein kinase 2, as revealed by testing of a panel of more than 200 protein kinases [36]. PHII-7 became a promising potent derivative of indirubin with cytotoxic effects in multidrug resistant cells, which represent a major obstacle for chemotherapy in many human malignancies [37]. Indirubins carrying a $5^{\prime}$-carboxylate moiety (such as compound 7-bromo- $5^{\prime}$-carboxyindirubin- $3^{\prime}$-oxime) yielded a novel inverse binding mode with improved selectivity for DYRK kinases that are implicated in alternative pre-mRNA splicing and in pathologies associated with neurons, including Alzheimer's disease and Down syndrome [30]. Finally, 5-diphenylacetamido-indirubin- $3^{\prime}$-oxime was described as a novel mitochondria-targeting agent with antileukemic activities [31].

Due to the planarity of structure, the developed hydrogen bonds and hydrophobic $\pi$-interactions and the rigid crystal structure indirubins generally suffer from low water solubility [38]. Achieving an increased, though not excessive, water solubility, without loss of bioactivity, represents a major goal in the synthesis of new indirubins [20]. To this end, attempts to intervene in the scaffold of indirubin (e.g., the conversion of $3^{\prime}$-carboxyl group to an oxime) and to destroy the planarity of indirubins have been made [39]. Alternatively, chemical modifications by adding polar hydrophilic groups to the scaffold were accomplished, as in the case of novel analogues of 6-bromo-indirubin- $3^{\prime}$ oxime [40]. The latter substances were then successfully applied to alter circadian rhythm in cell cultures [40]. Lately, indirubin-5-carboxamides, a novel class of indirubins carrying amide substituents with basic centers, were generated. Here quaternization or protonation of the alkylamino substituents improved their solubility, also without loss of bioactivity [41]. The recently developed $5^{\prime}-\mathrm{OH}-5-$ nitro-indirubin oxime (AGM130) had improved solubility compared to indirubin and was effectively applied to induce apoptosis of CML cells that were resistant to imatinib, a blocker of the pathological BCR/ABL fusion protein [32]. Additionally, extensive series of more soluble halogenated analogues have been generated, as reviewed elsewhere [13, 42]. Also the structure of meisoindigo has been modified and the derivatives have been tested in a panel of cancer cells [43]. The substance (E)-1-(2-(4-methylpiperazin-1-yl)ethyl)-[3,3' biindolinylidene]-2,2 ${ }^{\prime}$-dione (5-4) was at least 40 times better soluble than meisoindigo and exhibited little or no tendency to aggregate in solution and was capable of significantly extending the lifespans of animals in a K562 tumor xenografts model [43].

Besides the attempts to increase solubility of the indirubins, studies aiming to increase their in vivo bioavailability have been performed. These include, for example, the establishment of supersaturatable self-microemulsifying drug delivery system (S-SMEDDS) that improved indirubin's release in vitro and its bioavailability in rats when orally applied [44]. In another study use of a self-nanoemulsifying drug delivery system (SNEDDS) increased oral bioavailability of E804 by $~ 980 \%$ when compared with the aqueous suspension [45].

Typical features of some of these above-mentioned indirubins as well as their structures are depicted in Table 1. 


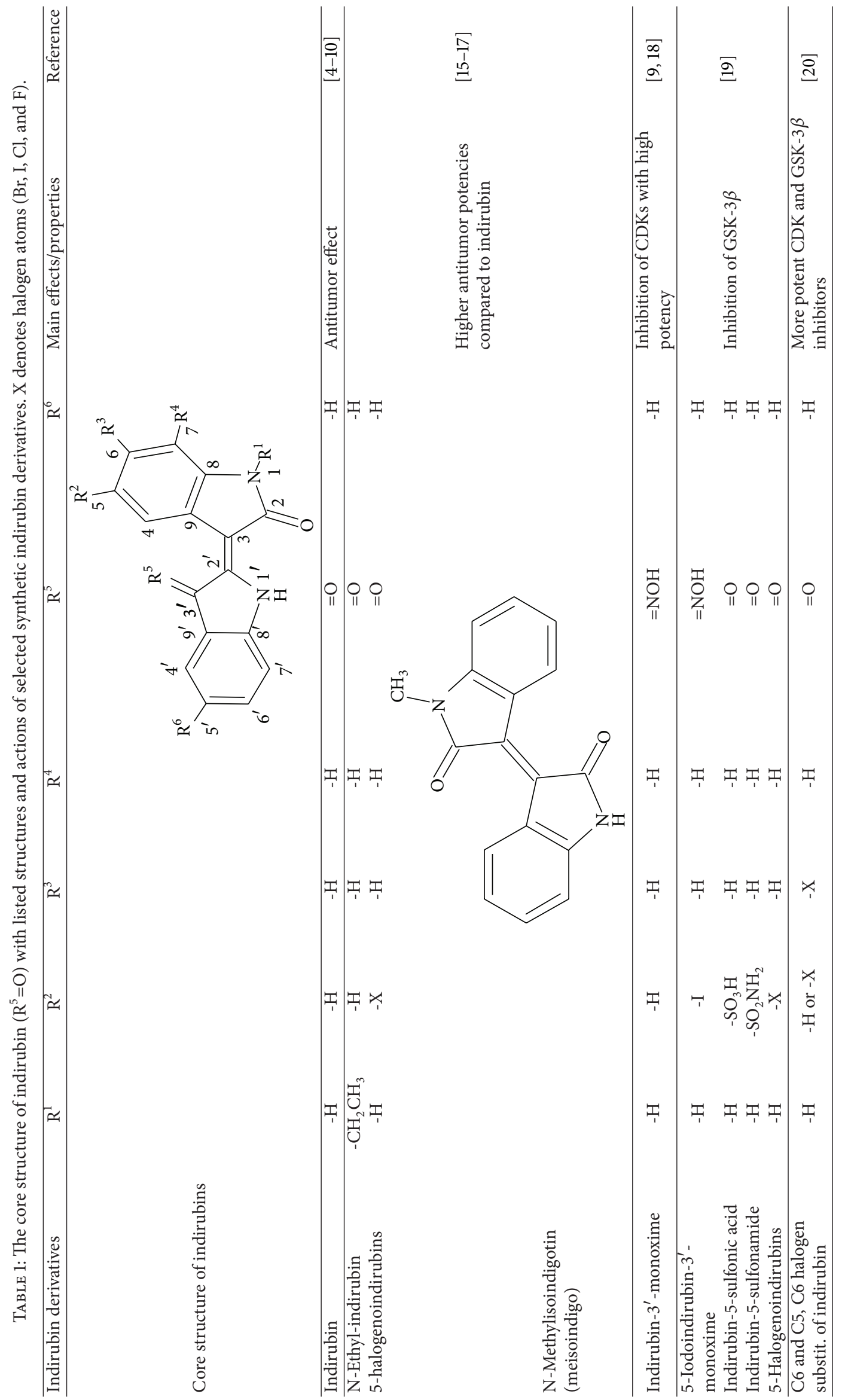




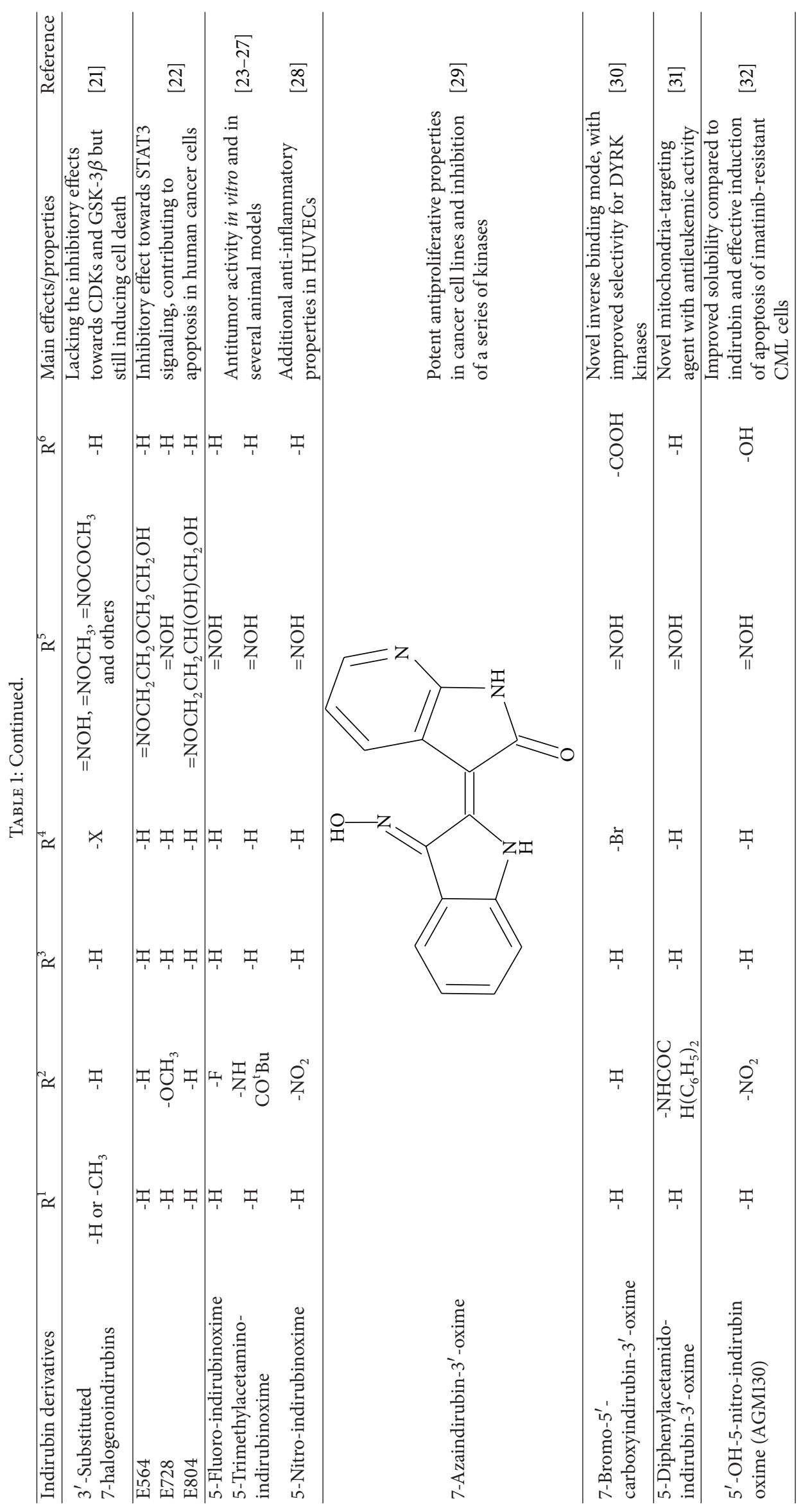




\section{Proteins and Signaling Pathways Targeted by Indirubins}

The intensive research during the several last decades on indirubins revealed that these substances interact with different proteins and influence a number of signaling pathways. The main effects of indirubins include the inhibition of cell proliferation as well as induction of cell differentiation and cell death, as surveyed below.

3.1. Indirubin-Mediated Inhibition of Cell Proliferation and Induction of Differentiation. The suppression of malignant transformation in CML patients by indirubin, reported in the 1980s, was originally attributed to DNA intercalation $[17,46]$ as well as interference with microtubule polymerization [17]. Only later, the potent inhibition of CDKs and of GSK$3 \beta$ was found to contribute mainly to the antiproliferative effects of indirubins $[9,19]$. Besides these effects, indirubin from Realgar-Indigo naturalis formula used for APL patient treatment caused intensified ubiquitination/degradation of the promyelocytic leukemia- (PML-) retinoic acid receptor alpha (RARalpha) oncoprotein [47].

CDKs are very important regulators of the eukaryotic cell cycle [48]. Identification of CDKs as specific molecular targets of indirubins was reported by the group of Meijer [9]. Their work discovered the cocrystal structure of a complex of CDK2 and indirubin- $3^{\prime}$-monoxime, thereby demonstrating indirubin- $3^{\prime}$-monoxime interaction with the ATP-binding site of CDK2. In a later study, indirubin- $3^{\prime}$-monoxime potently inhibited cell proliferation of a mammary carcinoma cell line (MCF-7), by arresting the cells in the G2/M phase of the cell cycle, possibly by inhibiting CDK1 [49]. Furthermore, indirubin-3'-oxime suppresses in a CDK2-dependent manner abnormal centriole duplication induced by the human papillomavirus in a human osteosarcoma cell line [50]. The compound also increases the level of the CDK inhibitor $\mathrm{p} 27^{\mathrm{Kip} 1}$ in a human neuroblastoma cell line (LA-N-1) and reduced the expression of CDK2 and cyclin E, leading to cell cycle arrest at the G0/G1 phase [51].

Cell cycle-inhibitory (cytostatic) activity of indirubins was additionally attributed to the inhibition of GSK-3 $\beta$ [19], a regulatory serine/threonine kinase related to CDKs. GSK$3 \beta$ exhibits a plethora of cellular effects and is a therapeutic target for the treatment of cancer, chronic inflammation, type II diabetes, and other diseases [52, 53]. Such inhibition by 6 -bromoindirubin acetoxime was important not only for suppression of migration of adult gliomas [54] but also for inhibiting migration of pediatric glioma, by instigating cytoskeletal rearrangement [55].

Another mechanism for how indirubins contribute to their cytostatic effects is the interaction with the aryl hydrocarbon receptor (AhR) [56]. AhR plays an important role in the cellular metabolism of xenobiotics, and AhR signaling is considered as a promising drug target, particularly for cancer, inflammation, and autoimmune diseases [57]. Indirubin and indigo bind to AhR with high affinities [58]. These compounds are present in normal human urine at $0.2 \mathrm{nM}$ concentration and at such physiological levels they may activate AhR-mediated signaling mechanisms in vivo [59]. The kinase-independent cytostatic effect of indirubins was demonstrated using 1-methyl-indirubins, a subfamily of kinase-inactive indirubins, and involved the AhRmediated expression of a potent CDK2 inhibitor p2 $7^{\text {Kip1 }}$ [56]. In another study, overexpression of the AhR in the absence of exogenous ligands was found to rapidly disrupt centriole duplication control in breast cancer cells [60]. Nonetheless, the AhR agonist, indirubin- $3^{\prime}$-oxime, and a kinase-inactive inhibitor, 1-methyl-indirubin- $3^{\prime}$-oxime, still significantly reduce centriole overduplication stimulated by ectopic AhR expression [60]. The role of indirubins in AhR signaling seems to be complex, as indirubin activated AhR in human $\mathrm{HaCaT}$ and $\mathrm{HepG} 2$ cells with significantly higher, although still transient, potency as compared with dioxin, the prototypical AhR ligand [61].

Finally, indirubins may induce cell differentiation or inhibit cellular proliferation by suppression of protooncogenes or by interference with growth factor signaling. For example, the indirubin derivative meisoindigo was shown in the 1990s to induce differentiation of ML-1 human myeloblastic leukemia cells and to downregulate c-myb gene expression [62]. Indirubin- $3^{\prime}$-monoxime suppresses the autophosphorylation of fibroblast growth factor receptor 1 (FGFR1) and, by blocking receptor-mediated cell signaling, also inhibits proliferation of NIH/3T3 fibroblasts [63]. Indirubin- $3^{\prime}$-monoxime further potently suppresses Notch1 signaling in a manner that is dependent on GSK- $3 \beta$ but independent of proteosomal degradation [64]. The compound 5nitro-indirubinoxime (denoted incorrectly as substituted at the five-prime position on the indirubin molecule) inhibits the betal integrin/focal adhesion kinase/Akt pathway and thereby decreases the metastatic ability of human head and neck cancer cells [26]. Indirubin- $3^{\prime}$-monoxime in human leukemic KBM-5 cells suppresses tumor necrosis factor(TNF-) $\alpha$-induced activation of NF- $\kappa \mathrm{B}$, a central transcription factor involved in the regulation of various inflammatory genes as well as antiapoptotic genes $[65,66]$. Although the roles of NF- $\kappa$ B in different types of cancer are complex [67], these data indicate that the antiproliferative and the antiinflammatory activity previously assigned to indirubin [28] may be mediated in part through the suppression of the NF$\kappa \mathrm{B}$ pathway.

\subsection{Indirubin-Mediated Induction of Cell Death. Additional} important hallmarks of the indirubin-related effects, which include induction of proapoptotic genes, interference with mitochondrial function, and STAT signaling leading to cell death, are surveyed below.

Indirubin-5-nitro- $3^{\prime}$-monoxime in human lung cancer cells induces apoptosis via p53- and mitochondria-dependent pathways [68]. The compound additionally stimulates cell cycle arrest as well as apoptosis, as shown with carcinoma cells. This process was instigated after the release of cytochrome $\mathrm{c}$ and the activation of caspases. Also, indirubin$3^{\prime}$-monoxime causes apoptosis in human cervical, hepatoma, and colon cancer cells by inducing proapoptotic Bcl-2 family members Bid and Bax [69], as depicted in Figure 1. 


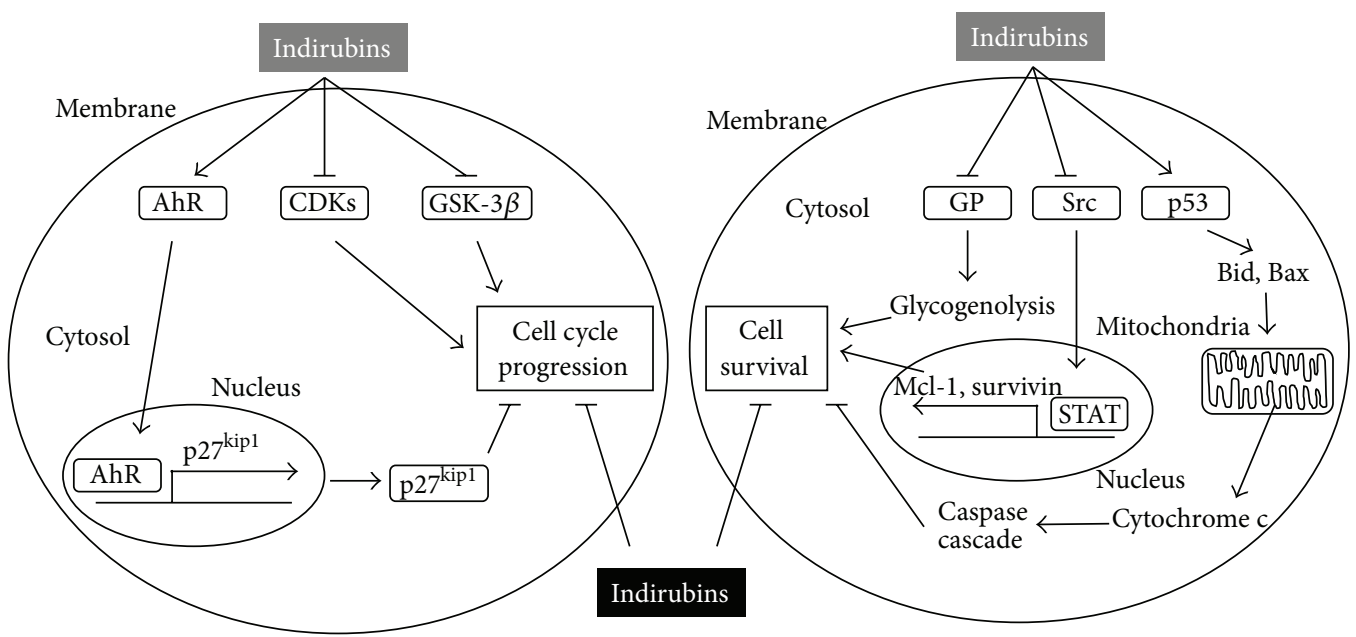

FIGURE 1: Cellular effects mediated by indirubins. By direct inhibition of CDKs and GSK-3 $\beta$ and by the activation of AhR-mediated upregulation of cell cycle inhibitor p $27^{\text {Kip } 1}$, indirubins inhibit cell cycle progression. They also suppress cell survival by inducing caspasemediated apoptosis upon interfering with mitochondrial function and affecting Src and STAT-mediated expression of cell survival proteins. Furthermore, by inhibiting GP indirubins suppress glycogenolysis, thus hampering the glucose supply of cancer cells. These effects lead to inhibition of cell cycle progression and induction of cell death $(\rightarrow$ activation/release; $\perp$ inhibition $)$.

Indirubin- $3^{\prime}$-oxime (synonym of indirubin- $3^{\prime}$-monoxime) further alters mitochondrial function in human neuroblastoma cells by curtailing the mitochondrial membrane potential and elevating the levels of reactive oxygen species [51]. Moreover, this substance induces apoptotic and autophagic death in acute lymphoblastic as well as chronic myelogenous human leukemia cells, by a mechanism possibly involving caspase-3 [70].

An additional indirubin derivative, $5^{\prime}$-methoxyindirubin, induces apoptosis in human neuroblastoma cells [71]. Treatment of melanoma cells with 8 -Rha- $\beta$-indirubin enhances their sensitivity for death ligands, overcoming their resistance to two important factors, namely, TNF- $\alpha$-related apoptosis-inducing ligand (TRAIL) and CD95 agonists [72]. A similar drug-potentiation effect was observed for the novel indirubin derivative PHII-7 that increased adriamycin cytotoxicity (via inhibiting P-glycoprotein expression) and cell apoptosis in MCF-7/ADR human breast cancer cells [37]. Application of 6-bromo-indirubin-3' effectively abrogates cellular growth and induces apoptosis in both breast cancer and bladder carcinoma cell lines and prevents tumor cell resistance towards TRAIL [73]. Finally, 5-diphenylacetamido-indirubin- $3^{\prime}$-oxime was recently described as a novel mitochondria-targeting agent with antileukemic activities that is able to increase the opening of mitochondrial permeability transition pores [31].

In many reported cases, indirubin-induced apoptosis was caused by an interference with STAT signaling. For example, indirubin derivatives E564, E728, and E804 potently block constitutive STAT3 signaling in human breast and prostate cancer cells [22]. The compound E804, in addition, directly inhibits Src, a kinase acting upstream STAT proteins, and suppresses the expression of antiapoptotic proteins Mcl-1 and survivin [22]. Importantly, a subtoxic concentration of
E804 resensitized cancer treatment-resistant cells (MV4-11R) by inhibiting STAT1, STAT3, and STAT5 signaling and by abolishing survivin expression [74]. In human K562 chronic myelogenous leukemia cells, E804 potently suppresses STAT5 signaling and induces apoptosis [75]. E738 works as a novel dual inhibitor of STAT-activating kinases, including Janus kinases (JAKs) and Src family kinases (SFKs), thereby inducing apoptosis in human pancreatic cancer cells [76]. In human melanoma cells, 6-bromoindirubin- $3^{\prime}$-oxime inhibits JAK and STAT3 signaling [77] and 7-bromoindirubin (designated as MLS-2438) inhibits STAT3 and Akt signaling, with both derivatives inducing apoptosis [78].

Besides the ability to induce apoptosis, indirubins also induce necrosis. Specifically, indirubin- $3^{\prime}$-monoxime causes necrosis in human breast carcinoma cell line [79] and 7bromoindirubin- $3^{\prime}$-oxime instigates necrosis in human THP1 macrophages and in a human mesothelioma cell line [80].

Finally, indirubin-5-sulphonate allosterically inhibits glycogen phosphorylase (GP) [81]. This effect might be important for the depletion of glucose in cancer cells, thereby hampering their survival.

The main pathways of indirubin-mediated effects on proliferation and cell death are outlined in Figure 1.

\section{Indirubins Counteracting Proliferative Diseases}

In addition to the in vitro effects outlined above, indirubins were tested and their potency was shown in many preclinical models. These studies clearly showed the potential therapeutic use of indirubins for counteracting proliferative diseases, such as cancer, pathological angiogenesis, restenosis, and psoriasis, as reviewed in the following sections. 


\section{Indirubins Thwart Cancer and Pathological Angiogenesis}

One of the first animal studies pointing to an efficacy of indirubins in the treatment of cancer involved the application of various indirubins to skin xenografts. Specifically, direct injection of indirubins into xenografts of RK3Eras rat kidney epithelial cells harboring the k-ras gene was shown to reduce cancer in male Sprague-Dawley rats [23]. In the aforementioned study, several indirubins such as 5-nitro-indirubinoxime, 5-fluoro-indirubinoxime, and 5-trimethylacetamino-indirubinoxime were injected every other day for 10 days, and this significantly inhibited tumor growth and induced apoptosis [23]. Indirubin-3-monoxime was applied to a murine benzo $(\alpha)$ pyrene $[\mathrm{B}(\alpha) \mathrm{P}]$-induced lung cancer model at a dose of $10 \mathrm{mg} / \mathrm{kg}$ for $5 \mathrm{~d}$ per week, and this resulted in a reduced adenocarcinoma growth due to apoptosis [82]. Clinically, treatment of a CML patient using imatinib in combination with indirubin and meisoindigo resulted in complete cytogenetic response and the longest record of survival among CML patients in the literature [83]. The isoindigo derivative natura-alpha (N-methyl- $\Delta 3,3^{\prime}-$ dihydroindole-2,2' -diketone) demonstrated both in vitro and in vivo effects. In case of the former, growth of both androgendependent (LNCaP) and androgen-independent (LNCaPAI, PC-3, and DU145) prostate cancer cells was inhibited, whereas the compound inhibited androgen receptor signaling upon coinjection with human prostate cell lines in a xenograft model using nude mice [84]. Importantly, naturaalpha also reduced tumor volume in a patient with hormonerefractory metastatic prostate cancer [84]. Indirubin- $3^{\prime}$ monoxime also induced apoptosis in oral cancer cell lines in vitro, through activation of cytochrome $\mathrm{c}$ and inhibition of a number of factors including focal adhesion kinase, urokinase-type plasminogen inhibitor, and matrix metalloproteinase. When applied topically to mice in an adhesive gel, indirubin- $3^{\prime}$-monoxime suppressed oral cancer through the downregulation of survivin [85].

In addition to their ability to suppress primary tumour growth, indirubins also suppress lung tumour metastases, as demonstrated by administration of 6-bromo-indirubin- $3^{\prime}$ oxime in a 4T1 mouse model for aggressive breast cancer [86]. These findings were fully consistent with in vitro data showing that 6-bromo-indirubin- $3^{\prime}$-oxime inhibited adhesion, migration, and invasion of a variety of metastatic cell types. This was achieved by influencing the JAK/STAT3 signaling pathway and inhibiting several kinase cascades involved in the metastasizing of cancer cells. Such competence of indirubins to influence multilaterally several cellular signaling networks and metabolism strongly suggests that indirubins could be used as drugs, either alone or in combination with conventional antineoplastic agents, to overcome multidrug resistance, which represents a major impediment to the effective therapy of many human malignancies [87].

The experimental evidence for the importance of inducing and sustaining angiogenesis, the formation of new blood vessels from existing ones, for tumor growth is compelling $[88,89]$. Pathological angiogenesis is a hallmark of cancer as well as various ischaemic and inflammatory diseases [90-92].
Therefore, the ability of indirubins to inhibit angiogenesis, as outlined below, may significantly contribute to the inhibition of tumor growth and metastasis.

The antiangiogenic potential of indirubin- $3^{\prime}$-monoxime was discovered in vivo in an automated quantitative screening assay using transgenic zebrafish embryos and confirmed in vitro by applying tube formation and proliferation in human umbilical vein endothelial cells HUVECs [93]. In a subsequent study, indirubin- $3^{\prime}$-monoxime was applied to endothelial cells, which not only influenced proliferation, cell cycle, apoptosis, migration, and tube formation but also acted on AKT, p38, ERK1/2, c-Src, and GSK$3 \beta$ kinases. Indirubin's scaffold was therefore suggested to be promising for the development of novel antiangiogenic drugs [94]. Additionally, the inhibitory effect of the parent compound indirubin on angiogenesis was visualized in transgenic zebrafish embryos and confirmed in endothelial cell cultures [95]. 5-Nitro-indirubinoxime reduced angiogenesis, primarily by inhibiting the expression of vascular endothelial growth factor VEGF [26]. This was shown in vivo using the chorioallantoic membrane (CAM) assay in fertilized chicken eggs and in the cornea of mice [26]. In $e x$ vivo assays, indirubin- $3^{\prime}$-monoxime was also able to inhibit the number of microvessels growing from the aortic rings, whereas in other in vivo tests using mice the compound induced neovascularization in matrigel plugs. The molecular mechanisms underlying the antiangiogenic effects of indirubin- $3^{\prime}$-monoxime in endothelial cells depended, at least partly, on the downregulation of the activation of VEGFR2 (vascular endothelial growth factor receptor 2) [96, 97]. The in vivo inhibitory effect of E804 on angiogenesis and tumor growth was shown in syngenic $\mathrm{Balb} / \mathrm{c}$ mice that were transplanted subcutaneously with colon cancer cells. Subsequently, the intratumor injections of E804 inhibited vascular growth of the inoculated allografts, as demonstrated by a decrease in both the microvessel density marker CD31 and the proliferative indicator Ki-67, but also by an increase in the apoptosis index [98]. The antiangiogenic effect of E804 was further corroborated in vitro by inhibition of proliferation, migration, and tube formation of HUVECs and in vivo by monitoring growth factor-induced neovessel formation in the matrigel plug model in mice [99]. These growth factors included VEGF and basic fibroblast growth factor (bFGF). Altogether, these data clearly show the potency of indirubins to suppress cancer growth, in part by inhibiting pathological angiogenesis.

\section{Indirubins Counteracting Restenosis}

Restenosis refers to the thickening of the arterial wall and is characterized not only by increased platelet and immune cell infiltration but also by increased migration and proliferation of vascular smooth muscle cells (VSMCs) into the intimal layer. Restenosis represents a serious clinical problem in patients undergoing balloon angioplasty and stenting and may result in life-threatening vessel occlusions $[100,101]$. Studies on VSMC proliferation in vitro and experimentally induced neointima formation in vivo 
revealed the inhibitory action of indirubin- $3^{\prime}$-monoxime on restenosis. In our previous work, indirubin- $3^{\prime}$-monoxime inhibited VSMC proliferation induced by the BB isoform of platelet-derived growth factor (PDGF-BB) by arresting cells in the G0/G1 phase of the cell cycle. Moreover, the indirubin derivative specifically blocked the phosphorylation of STAT3 upon PDGF, interferon $-\gamma$, and thrombin stimulation [102]. In a murine femoral artery cuff model, indirubin- $3^{\prime}$ monoxime prevented neointima formation while reducing both STAT3 phosphorylation and the amount of proliferating Ki67-positive cells. In addition, this compound increased endothelial nitric oxide production, thereby potentially ameliorating endothelial dysfunction [102]. A further study on indirubin- $3^{\prime}$-monoxime demonstrated that it inhibits the migration of vascular smooth muscle cells after stimulation with leukotriene or platelet-derived growth factor. Moreover, the compound suppresses leukotriene biosynthesis in monocytes by direct inhibition of 5-lipoxygenase [103]. Oral administration of indirubin- $3^{\prime}$-monoxime significantly retarded occlusion in a rat carotid artery-injury model as well as ADP- and collagen-induced platelet aggregation. This effect was due to the suppression of glycoprotein VImediated signaling pathways in platelets through blocking of phospholipase C $\gamma 2$ phosphorylation [104]. A further compound, 5-nitro-indirubinoxime (incorrectly designated as modified at the five-prime position), was applied to HUVECs and this inhibited the TNF- $\alpha$-induced anti-inflammatory response and the adhesion of U937 cells by decreasing the expression of the cell adhesion molecules ICAM-1 and VCAM-1 [28]. The above described inhibitory effects of indirubins on VSMC proliferation, platelet aggregation, and activation of endothelial cells showcase the potential use of indirubins, especially that of indirubin- $3^{\prime}$-monoxime, as lead compounds for preventing restenosis.

\section{Indirubins for Treating Psoriasis}

Psoriasis is a common inflammatory skin disease, affecting about $2 \%$ of the general population in the western world [105]. One of the hallmarks of this disease is an uncontrolled proliferation of keratinocytes, which is accompanied by abnormal differentiation of cells $[106,107]$. Mechanistic studies revealed that in psoriatic skin lesions indirubin treatment interferes with the proliferation and differentiation of keratinocytes, underscored by a decrease in proliferation marker PCNA and an increase in the expression of protective involucrin [108]. Indirubin additionally inhibits the activation of epidermal growth factor receptor (EGFR) as well as CDC25B gene expression induced by epidermal growth factor (EGF) [109]. In cultured human keratinocytes and in psoriatic lesions, indirubin also causes upregulation of claudin-1, which functions as major constituent of tight junction complexes that regulate the permeability of epithelia [110]. Application of 5nitro-indirubinoxime (incorrectly [111] designated as modified at the five-prime position) to mouse skin epidermal cells results in the inhibition of neoplastic cell transformation induced by EGF or 12-O-tetradecanoylphorbol-13-acetate (TPA). Such treatment additionally inhibits a number of activities induced by EGF or TPA, including those of Raf-1, MEK1/2, ERK1/2, JNK, and c-Jun. Also, in a mouse model of skin psoriasis, local application of indirubin and of indigo naturalis was demonstrated to be effective and safe [112]. In a recent study, indigo naturalis treatment was additionally shown to be effective in treating nail psoriasis in humans, a condition that is notoriously difficult to treat and which lacks standardized therapeutic regimens [113].

\section{Conclusions}

The use of indirubin and its derivatives in several clinical settings has been patented, as recently surveyed in another review [38], and holds promise for future therapeutic applications. In addition to the traditional use of indirubin in the treatment of CML, indirubin and its numerous derivatives were shown to be effective in counteracting many proliferative diseases, as demonstrated by cell culture studies and preclinical models. This review highlights the contemporary progress in elucidating the mechanisms of how indirubins influence multiple molecular pathways, leading to cell cycle inhibition and apoptosis. Although the most pronounced effects of indirubin and its derivatives were seen in cancer, treatment of psoriasis and restenosis may also benefit from this group of compounds.

\section{The Key Abbreviations Used}

$\begin{array}{ll}\text { AhR: } & \text { Aryl hydrocarbon receptor } \\ \text { bFGF: } & \text { Basic fibroblast growth factor } \\ \text { CDK: } & \text { Cyclin-dependent kinase } \\ \text { CML: } & \text { Chronic myelocytic leukemia } \\ \text { eNO: } & \text { Endothelial nitric oxide } \\ \text { EGF: } & \text { Epidermal growth factor } \\ \text { EGFR: } & \text { Epidermal growth factor receptor (EGFR) } \\ \text { FGFR1: } & \text { Fibroblast growth factor receptor 1 } \\ \text { GP: } & \text { Glycogen phosphorylase } \\ \text { GSK-3 } \beta: & \text { Glycogen synthase kinase-3 } \beta \\ \text { HUVECs: } & \text { Human umbilical vein endothelial cells } \\ \text { ICAM-1: } & \text { Intercellular adhesion molecule } 1 \\ \text { PDGF: } & \text { Platelet-derived growth factor } \\ \text { STAT: } & \text { Signal transducers and activators of } \\ & \text { transcription } \\ \text { TNF- } \alpha: & \text { Tumor necrosis factor- } \alpha \\ \text { TPA: } & \text { 12-O-Tetradecanoylphorbol-13-acetate } \\ \text { TRAIL: } & \text { TNF- } \alpha \text {-related apoptosis-inducing factor } \\ & \text { ligand } \\ \text { VCAM-1: } & \text { Vascular cell adhesion molecule } 1 \\ \text { VEGF: } & \text { Vascular endothelial growth factor } \\ \text { VEGFR2: } & \text { Vascular endothelial growth factor } \\ & \text { receptor } 2\end{array}$

\section{Conflict of Interests}

The authors declare that there is no conflict of interests regarding the publication of this paper. 


\section{Acknowledgment}

The authors thank Aner Gurvitz for his careful reading and editing of this paper.

\section{References}

[1] D. J. Newman and G. M. Cragg, "Natural products as sources of new drugs over the 30 years from 1981 to 2010," Journal of Natural Products, vol. 75, no. 3, pp. 311-335, 2012.

[2] A. D. Kinghorn, L. Pan, J. N. Fletcher, and H. Chai, "The relevance of higher plants in lead compound discovery programs," Journal of Natural Products, vol. 74, no. 6, pp. 1539-1555, 2011.

[3] A. G. Atanasov, B. Waltenberger, E. M. Pferschy-Wenzig et al., "Discovery and resupply of pharmacologically active plantderived natural products: a review," Biotechnology Advances, 2015.

[4] "Clinical and experimental studies in the treatment of chronic granulocytic leukemia with indirubin," Zhonghua Nei Ke Za Zhi, vol. 18, no. 2, pp. 83-88, 1979.

[5] G. Y. Wu and F. D. Fang, "Studies on the mechanism of indirubin action in the treatment of chronic granulocytic leukemia. II. Effects of indirubin on nucleic acid and protein synthesis in animal transplantable tumor cells and normal proliferating cells in vitro (author's transl)," Zhongguo Yi Xue Ke Xue Yuan Xue Bao, vol. 2, no. 2, pp. 83-87, 1980.

[6] M. Z. Ma and B. Y. Yao, "Progress in indirubin treatment of chronic myelocytic leukemia," Journal of Traditional Chinese Medicine, vol. 3, no. 3, pp. 245-248, 1983.

[7] Z. Xiao, Y. Hao, B. Liu, and L. Qian, "Indirubin and meisoindigo in the treatment of chronic myelogenous leukemia in China," Leukemia \& Lymphoma, vol. 43, no. 9, pp. 1763-1768, 2002.

[8] Z. N. Zhang, E. K. Liu, T. L. Zheng, and D. G. Li, “Treatment of chronic myelocytic leukemia (CML) by traditional Chinese medicine and Western medicine alternately," Journal of Traditional Chinese Medicine, vol. 5, no. 4, pp. 246-248, 1985.

[9] R. Hoessel, S. Leclerc, J. A. Endicott et al., "Indirubin, the active constituent of a Chinese antileukaemia medicine, inhibits cyclin-dependent kinases," Nature Cell Biology, vol. 1, no. 1, pp. 60-67, 1999.

[10] S. Jiang, G. Yu, and J. Cao, "Adverse effect of indirubin on the cardiovascular system, a report of 3 cases," Chinical Journal of Hematology, vol. 7, no. 1, p. 30, 1986.

[11] G. Eisenbrand, F. Hippe, S. Jakobs, and S. Muehlbeyer, "Molecular mechanisms of indirubin and its derivatives: novel anticancer molecules with their origin in traditional Chinese phytomedicine," Journal of Cancer Research and Clinical Oncology, vol. 130, no. 11, pp. 627-635, 2004.

[12] G. Karapetyan, K. Chakrabarty, M. Hein, and P. Langer, "Synthesis and bioactivity of carbohydrate derivatives of indigo, its isomers and heteroanalogues," ChemMedChem, vol. 6, no. 1, pp. 25-37, 2011.

[13] K. Vougogiannopoulou and A. L. Skaltsounis, "From tyrian purple to kinase modulators: naturally halogenated indirubins and synthetic analogues," Planta Medica, vol. 78, no. 14, pp. 15151528, 2012.

[14] Y. Wang, P. M. Hoi, J. Y. W. Chan, and S. M. Y. Lee, "New perspective on the dual functions of indirubins in cancer therapy and neuroprotection," Anti-Cancer Agents in Medicinal Chemistry, vol. 14, no. 9, pp. 1213-1219, 2014.
[15] X. J. Ji and F. R. Zhang, "Studies on antineoplastic action of indirubin derivatives and analogs and their structure-activity relationships," Acta Pharmaceutica Sinica, vol. 20, no. 2, pp. 137139, 1985.

[16] Y. C. Gu, G. L. Li, Y. P. Yang, J. P. Fu, and C. Z. Li, "Synthesis of some halogenated indirubin derivatives," Yao Xue Xue Bao, vol. 24, no. 8, pp. 629-632, 1989.

[17] X. J. Ji, X. M. Liu, K. Li, R. H. Chen, and L. G. Wang, "Pharmacological studies of meisoindigo: absorption and mechanism of action," Biomedical and Environmental Sciences, vol. 4, no. 3, pp. 332-337, 1991.

[18] C. Li, Y. Go, Z. Mao et al., "The synthesis, antileukemic activity, and crystal structures of indirubin derivatives," Bulletin of the Chemical Society of Japan, vol. 69, no. 6, pp. 1621-1627, 1996.

[19] S. Leclerc, M. Garnier, R. Hoessel et al., "Indirubins inhibit glycogen synthase kinase-3 $\beta$ and $\mathrm{CDK} 5 / \mathrm{P} 25$, two protein kinases involved in abnormal tau phosphorylation in Alzheimer's disease. A property common to most cyclindependent kinase inhibitors?" Journal of Biological Chemistry, vol. 276, no. 1, pp. 251-260, 2001.

[20] P. Polychronopoulos, P. Magiatis, A. L. Skaltsounis et al., "Structural basis for the synthesis of indirubins as potent and selective inhibitors of glycogen synthase kinase-3 and cyclindependent kinases," Journal of Medicinal Chemistry, vol. 47, no. 4, pp. 935-946, 2004.

[21] Y. Ferandin, K. Bettayeb, M. Kritsanida et al., “ 3 ' -substituted 7halogenoindirubins, a new class of cell death inducing agents," Journal of Medicinal Chemistry, vol. 49, no. 15, pp. 4638-4649, 2006.

[22] S. Nam, R. Buettner, J. Turkson et al., "Indirubin derivatives inhibit Stat3 signaling and induce apoptosis in human cancer cells," Proceedings of the National Academy of Sciences of the United States of America, vol. 102, no. 17, pp. 5998-6003, 2005.

[23] S. A. Kim, Y. C. Kim, S. W. Kim et al., "Antitumor activity of novel indirubin derivatives in rat tumor model," Clinical Cancer Research, vol. 13, no. 1, pp. 253-259, 2007.

[24] S. A. Kim, S. W. Kim, S. Chang, J. H. Yoon, and S. G. Ahn, " 5 '-nitro-indirubinoxime induces G2/M cell cycle arrest and apoptosis in human KB oral carcinoma cells," Cancer Letters, vol. 274, no. 1, pp. 72-77, 2009.

[25] J. H. Yoon, S. A. Kim, S. M. Kwon et al., " 5 '-Nitroindirubinoxime induces G1 cell cycle arrest and apoptosis in salivary gland adenocarcinoma cells through the inhibition of Notch-1 signaling," Biochimica et Biophysica Acta-General Subjects, vol. 1800, no. 3, pp. 352-358, 2010.

[26] S. A. Kim, S. M. Kwon, J. A. Kim, K. W. Kang, J. H. Yoon, and S. G. Ahn, " 5 '-Nitro-indirubinoxime, an indirubin derivative, suppresses metastatic ability of human head and neck cancer cells through the inhibition of Integrin $\beta 1 / F A K / A k t$ signaling," Cancer Letters, vol. 306, no. 2, pp. 197-204, 2011.

[27] H. E. Yoon, S. A. Kim, H. S. Choi, M. Y. Ahn, J. H. Yoon, and S. G. Ahn, "Inhibition of Plk1 and Pin 1 by 5 ' -nitro-indirubinoxime suppresses human lung cancer cells," Cancer Letters, vol. 316, no. 1, pp. 97-104, 2012.

[28] E. J. Kim, W. H. Park, S. G. Ahn, J. H. Yoon, S. W. Kim, and S. A. Kim, " 5 '-nitro-indirubinoxime inhibits inflammatory response in TNF- $\alpha$ stimulated human umbilical vein endothelial cells," Atherosclerosis, vol. 211, no. 1, pp. 77-83, 2010.

[29] M. Kritsanida, P. Magiatis, A. L. Skaltsounis, Y. Peng, P. Li, and L. P. Wennogle, "Synthesis and antiproliferative activity of 7azaindirubin- $3^{\prime}$-oxime, a 7-aza isostere of the natural indirubin 
pharmacophore," Journal of Natural Products, vol. 72, no. 12, pp. 2199-2202, 2009.

[30] V. Myrianthopoulos, M. Kritsanida, N. Gaboriaud-Kolar et al., "Novel inverse binding mode of indirubin derivatives yields improved selectivity for DYRK kinases," ACS Medicinal Chemistry Letters, vol. 4, no. 1, pp. 22-26, 2013.

[31] J. H. Song, J. Lee, K. Cho et al., "5-diphenylacetamidoindirubin- $3^{\prime}$-oxime as a novel mitochondria-targeting agent with anti-leukemic activities," Molecular Carcinogenesis, 2015.

[32] W. S. Kim, M. J. Lee, D. H. Kim et al., “5'-OH-5-nitro-Indirubin oxime (AGM130), an Indirubin derivative, induces apoptosis of Imatinib-resistant chronic myeloid leukemia cells," Leukemia Research, vol. 37, no. 4, pp. 427-433, 2013.

[33] L. Meijer, A. L. Skaltsounis, P. Magiatis et al., "GSK-3-selective inhibitors derived from Tyrian purple indirubins," Chemistry \& Biology, vol. 10, no. 12, pp. 1255-1266, 2003.

[34] J. E. Darnell Jr., "STATs and gene regulation," Science, vol. 277, no. 5332, pp. 1630-1635, 1997.

[35] T. E. Battle and D. A. Frank, "The role of STATs in apoptosis," Current Molecular Medicine, vol. 2, no. 4, pp. 381-392, 2002.

[36] X. Cheng, K. H. Merz, S. Vatter, J. Christ, S. Wölfl, and G. Eisenbrand, " $7,7^{\prime}$-diazaindirubin - a small molecule inhibitor of casein kinase 2 in vitro and in cells," Bioorganic and Medicinal Chemistry, vol. 22, no. 1, pp. 247-255, 2014.

[37] R. Shi, W. Li, X. Zhang et al., "A novel indirubin derivative PHII-7 potentiates adriamycin cytotoxicity via inhibiting Pglycoprotein expression in human breast cancer MCF-7/ADR cells," European Journal of Pharmacology, vol. 669, no. 1-3, pp. 38-44, 2011.

[38] N. Gaboriaud-Kolar, K. Vougogiannopoulou, and A. Skaltsounis, "Indirubin derivatives: a patent review (2010-present)," Expert Opinion on Therapeutic Patents, vol. 25, no. 5, pp. 583593, 2015.

[39] R. Jautelat, T. Brumby, M. Schäfer et al., "From the insoluble dye indirubin towards highly active, soluble CDK2-inhibitors," ChemBioChem, vol. 6, no. 3, pp. 531-540, 2005.

[40] K. Vougogiannopoulou, Y. Ferandin, K. Bettayeb et al., "Soluble $3^{\prime}, 6$-substituted indirubins with enhanced selectivity toward glycogen synthase kinase -3 alter circadian period," Journal of Medicinal Chemistry, vol. 51, no. 20, pp. 6421-6431, 2008.

[41] X. Cheng, P. Rasqué, S. Vatter, K. H. Merz, and G. Eisenbrand, "Synthesis and cytotoxicity of novel indirubin-5carboxamides," Bioorganic \& Medicinal Chemistry, vol. 18, no. 12, pp. 4509-4515, 2010.

[42] N. Gaboriaud-Kolar, S. Nam, and A. L. Skaltsounis, "A colorful history: the evolution of indigoids," Progress in the Chemistry of Organic Natural Products, vol. 99, pp. 69-145, 2014.

[43] X. K. Wee, T. Yang, and M. L. Go, "Exploring the anticancer activity of functionalized isoindigos: synthesis, drug-like potential, mode of action and effect on tumor-induced xenografts," ChemMedChem, vol. 7, no. 5, pp. 777-791, 2012.

[44] Z. Q. Chen, Y. Liu, J. H. Zhao, L. Wang, and N. P. Feng, "Improved oral bioavailability of poorly water-soluble indirubin by a supersaturatable self-microemulsifying drug delivery system," International Journal of Nanomedicine, vol. 7, pp. 1115$1125,2012$.

[45] N. Heshmati, X. Cheng, G. Eisenbrand, and G. Fricker, "Enhancement of oral bioavailability of E804 by self-nanoemulsifying drug delivery system (SNEDDS) in rats," Journal of Pharmaceutical Sciences, vol. 102, no. 10, pp. 3792-3799, 2013.
[46] G. Y. Wu, J. Z. Liu, F. D. Fang, and J. Zuo, "Studies on the mechanism of indirubin action in the treatment of chronic granulocytic leukemia. V. Binding between indirubin and DNA and identification of the type of binding," Scientia Sinica. Series B, vol. 25, no. 10, pp. 1071-1079, 1982.

[47] L. Wang, G. B. Zhou, P. Liu et al., "Dissection of mechanisms of Chinese medicinal formula Realgar-Indigo naturalis as an effective treatment for promyelocytic leukemia," Proceedings of the National Academy of Sciences of the United States of America, vol. 105, no. 12, pp. 4826-4831, 2008.

[48] D. O. Morgan, "Principles of CDK regulation," Nature, vol. 374, no. 6518, pp. 131-134, 1995.

[49] D. Marko, S. Schätzle, A. Friedel et al., "Inhibition of cyclindependent kinase 1 (CDK1) by indirubin derivatives in human tumour cells," British Journal of Cancer, vol. 84, no. 2, pp. 283289, 2001.

[50] S. Duensing, A. Duensing, D. C. Lee et al., "Cyclin-dependent kinase inhibitor indirubin- $3^{\prime}$-oxime selectively inhibits human papillomavirus type 16 E7-induced numerical centrosome anomalies," Oncogene, vol. 23, no. 50, pp. 8206-8215, 2004.

[51] X. M. Liao and K. N. Leung, "Indirubin-3"-oxime induces mitochondrial dysfunction and triggers growth inhibition and cell cycle arrest in human neuroblastoma cells," Oncology Reports, vol. 29, no. 1, pp. 371-379, 2013.

[52] J. A. Bertrand, S. Thieffine, A. Vulpetti et al., "Structural characterization of the GSK-3 $\beta$ active site using selective and non-selective ATP-mimetic inhibitors," Journal of Molecular Biology, vol. 333, no. 2, pp. 393-407, 2003.

[53] D. S. Patel, N. Dessalew, P. Iqbal, and P. V. Bharatam, "Structurebased approaches in the design of GSK-3 selective inhibitors," Current Protein \& Peptide Science, vol. 8, no. 4, pp. 352-364, 2007.

[54] S. P. Williams, M. O. Nowicki, F. Liu et al., "Indirubins decrease glioma invasion by blocking migratory phenotypes in both the tumor and stromal endothelial cell compartments," Cancer Research, vol. 71, no. 16, pp. 5374-5380, 2011.

[55] J. V. Cockle, S. Picton, J. Levesley et al., "Cell migration in paediatric glioma; characterisation and potential therapeutic targeting," British Journal of Cancer, vol. 112, no. 4, pp. 693-703, 2015.

[56] M. Knockaert, M. Blondel, S. Bach et al., "Independent actions on cyclin-dependent kinases and aryl hydrocarbon receptor mediate the antiproliferative effects of indirubins," Oncogene, vol. 23, no. 25, pp. 4400-4412, 2004.

[57] C. Esser and A. Rannug, "The aryl hydrocarbon receptor in barrier organ physiology, immunology, and toxicology," Pharmacological Reviews, vol. 67, no. 2, pp. 259-279, 2015.

[58] U. Rannug, H. Bramstedt, and U. Nilsson, "The presence of genotoxic and bioactive components in indigo dyed fabricsa possible heatlh risk?" Mutation Research Letters, vol. 282, no. 3, pp. 219-225, 1992.

[59] J. Adachi, Y. Mori, S. Matsui et al., "Indirubin and indigo are potent aryl hydrocarbon receptor ligands present in human urine," The Journal of Biological Chemistry, vol. 276, no. 34, pp. 31475-31478, 2001.

[60] N. Korzeniewski, S. Wheeler, P. Chatterjee, A. Duensing, and S. Duensing, "A novel role of the aryl hydrocarbon receptor (AhR) in centrosome amplification-implications for chemoprevention," Molecular Cancer, vol. 9, article 153, 2010.

[61] P. Magiatis, P. Pappas, G. Gaitanis et al., "Malassezia yeasts produce a collection of exceptionally potent activators of the ah 
(dioxin) receptor detected in diseased human skin," Journal of Investigative Dermatology, vol. 133, no. 8, pp. 2023-2030, 2013.

[62] X. M. Liu, L. G. Wang, H. Y. Li, and X. J. Ji, "Induction of differentiation and down-regulation of $c$-myb gene expression in ML1 human myeloblastic leukemia cells by the clinically effective anti-leukemia agent meisoindigo," Biochemical Pharmacology, vol. 51, no. 11, pp. 1545-1551, 1996.

[63] Y. Zhen, V. Sørensen, Y. Jin, Z. Suo, and A. Więdłocha, "Indirubin-3'-monoxime inhibits autophosphorylation of FGFR1 and stimulates ERK1/2 activity via p38 MAPK," Oncogene, vol. 26, no. 44, pp. 6372-6385, 2007.

[64] M. J. Lee, M. Y. Kim, J. S. Mo et al., "Indirubin-3' -monoxime, a derivative of a Chinese anti-leukemia medicine, inhibits Notch1 signaling," Cancer Letters, vol. 265, no. 2, pp. 215-225, 2008.

[65] G. Sethi, K. S. Ahn, S. K. Sandur, X. Lin, M. M. Chaturvedi, and B. B. Aggarwal, "Indirubin enhances tumor necrosis factorinduced apoptosis through modulation of nuclear factor- $\kappa \mathrm{B}$ signaling pathway," The Journal of Biological Chemistry, vol. 281, no. 33, pp. 23425-23435, 2006.

[66] H. M. Shen and V. Tergaonkar, "NF $\kappa B$ signaling in carcinogenesis and as a potential molecular target for cancer therapy," Apoptosis, vol. 14, no. 4, pp. 348-363, 2009.

[67] Y. Ben-Neriah and M. Karin, "Inflammation meets cancer, with NF- $\kappa \mathrm{B}$ as the matchmaker," Nature Immunology, vol. 12 , no. 8 , pp. 715-723, 2011.

[68] J. W. Lee, M. J. Moon, H. Y. Min et al., "Induction of apoptosis by a novel indirubin-5-nitro- $3^{\prime}$-monoxime, a CDK inhibitor, in human lung cancer cells," Bioorganic \& Medicinal Chemistry Letters, vol. 15, no. 17, pp. 3948-3952, 2005.

[69] J. Shi and H. M. Shen, "Critical role of Bid and Bax in indirubin-3 $\prime^{\prime}$-monoxime-induced apoptosis in human cancer cells," Biochemical Pharmacology, vol. 75, no. 9, pp. 1729-1742, 2008.

[70] M. Y. Lee, Y. W. Liu, M. H. Chen et al., "Indirubin-3'monoxime promotes autophagic and apoptotic death in JM1 human acute lymphoblastic leukemia cells and K562 human chronic myelogenous leukemia cells," Oncology Reports, vol. 29, no. 5, pp. 2072-2078, 2013.

[71] H. Saito, K. Tabata, S. Hanada, Y. Kanda, T. Suzuki, and S. Miyairi, "Synthesis of methoxy- and bromo-substituted indirubins and their activities on apoptosis induction in human neuroblastoma cells," Bioorganic and Medicinal Chemistry Letters, vol. 21, no. 18, pp. 5370-5373, 2011.

[72] A. Berger, S. A. Quast, M. Plötz et al., "Sensitization of melanoma cells for death ligand-induced apoptosis by an indirubin derivative-enhancement of both extrinsic and intrinsic apoptosis pathways," Biochemical Pharmacology, vol. 81, no. 1, pp. 71-81, 2011.

[73] S. Braig, F. Bischoff, B. A. Abhari et al., "The pleiotropic profile of the indirubin derivative 6BIO overcomes TRAIL resistance in cancer," Biochemical Pharmacology, vol. 91, no. 2, pp. 157-167, 2014.

[74] J. Zhou, C. Bi, J. V. Janakakumara et al., "Enhanced activation of STAT pathways and overexpression of survivin confer resistance to FLT3 inhibitors and could be therapeutic targets in AML," Blood, vol. 113, no. 17, pp. 4052-4062, 2009.

[75] S. Nam, A. Scuto, F. Yang et al., "Indirubin derivatives induce apoptosis of chronic myelogenous leukemia cells involving inhibition of Stat5 signaling," Molecular Oncology, vol. 6, no. 3, pp. 276-283, 2012.

[76] S. Nam, W. Wen, A. Schroeder et al., "Dual inhibition of Janus and Src family kinases by novel indirubin derivative blocks constitutively-activated Stat3 signaling associated with apoptosis of human pancreatic cancer cells," Molecular Oncology, vol. 7, no. 3, pp. 369-378, 2013.

[77] L. Liu, S. Nam, Y. Tian et al., “6-Bromoindirubin-3'-oxime inhibits JAK/STAT3 signaling and induces apoptosis of human melanoma cells," Cancer Research, vol. 71, no. 11, pp. 3972-3979, 2011.

[78] L. Liu, M. Kritsanida, P. Magiatis et al., "A novel 7bromoindirubin with potent anticancer activity suppresses survival of human melanoma cells associated with inhibition of STAT3 and Akt signaling," Cancer Biology and Therapy, vol. 13, no. 13, pp. 1255-1261, 2012.

[79] E. Damiens, B. Baratte, D. Marie, G. Eisenbrand, and L. Meijer, "Anti-mitotic properties of indirubin- 3 '-monoxime, a CDK/GSK-3 inhibitor: induction of endoreplication following prophase arrest," Oncogene, vol. 20, no. 29, pp. 3786-3797, 2001.

[80] H. Li, A. Ambade, and F. Re, "Cutting edge: necrosis activates the NLRP3 inflammasome," The Journal of Immunology, vol. 183, no. 3, pp. 1528-1532, 2009.

[81] M. N. Kosmopoulou, D. D. Leonidas, E. D. Chrysina et al., "Binding of the potential antitumour agent indirubin-5sulphonate at the inhibitor site of rabbit muscle glycogen phosphorylase b: comparison with ligand binding to pCDK2cyclin a complex," European Journal of Biochemistry, vol. 271, no. 11, pp. 2280-2290, 2004.

[82] K. Ravichandran, A. Pal, and R. Ravichandran, "Effect of indirubin-3-monoxime against lung cancer as evaluated by histological and transmission electron microscopic studies," Microscopy Research and Technique, vol. 73, no. 11, pp. 10531058, 2010.

[83] F. Chen, L. Li, D. Ma et al., "Imatinib achieved complete cytogenetic response in a CML patient received 32-year indirubin and its derivative treatment," Leukemia Research, vol. 34, no. 2, pp. e75-e77, 2010.

[84] Y. Li, M. Ligr, J. P. McCarron et al., "Natura-alpha targets forkhead box M1 and inhibits androgen-dependent and independent prostate cancer growth and invasion," Clinical Cancer Research, vol. 17, no. 13, pp. 4414-4424, 2011.

[85] W. Y. Lo and N. W. Chang, "An indirubin derivative, indirubin$3^{\prime}$-monoxime suppresses oral cancer tumorigenesis through the downregulation of survivin," PLoS ONE, vol. 8, no. 8, Article ID e70198, 2013.

[86] S. Braig, C. A. Kressirer, J. Liebl et al., "Indirubin derivative 6BIO suppresses metastasis," Cancer Research, vol. 73, no. 19, pp. 6004-6012, 2013.

[87] C. Holohan, S. Van Schaeybroeck, D. B. Longley, and P. G. Johnston, "Cancer drug resistance: an evolving paradigm," Nature Reviews Cancer, vol. 13, no. 10, pp. 714-726, 2013.

[88] N. Bouck, V. Stellmach, and S. C. Hsu, "How tumors become angiogenic," Advances in Cancer Research, vol. 69, pp. 135-174, 1996.

[89] D. Hanahan and J. Folkman, "Patterns and emerging mechanisms of the angiogenic switch during tumorigenesis," Cell, vol. 86, no. 3, pp. 353-364, 1996.

[90] P. Carmeliet and R. K. Jain, "Angiogenesis in cancer and other diseases," Nature, vol. 407, no. 6801, pp. 249-257, 2000.

[91] J. Folkman, "Role of angiogenesis in tumor growth and metastasis," Seminars in Oncology, vol. 29, supplement 16, no. 6, pp. 15-18, 2002.

[92] D. Hanahan and R. A. Weinberg, "The hallmarks of cancer," Cell, vol. 100, no. 1, pp. 57-70, 2000. 
[93] T. C. Tran, B. Sneed, J. Haider et al., "Automated, quantitative screening assay for antiangiogenic compounds using transgenic zebrafish," Cancer Research, vol. 67, no. 23, pp. 11386-11392, 2007.

[94] S. Zahler, J. Liebl, R. Fürst, and A. M. Vollmar, "Anti-angiogenic potential of small molecular inhibitors of cyclin dependent kinases in vitro," Angiogenesis, vol. 13, no. 3, pp. 239-249, 2010.

[95] D. Alex, I. K. Lam, Z. Lin, and S. M. Y. Lee, "Indirubin shows anti-angiogenic activity in an in vivo zebrafish model and an in vitro HUVEC model," Journal of Ethnopharmacology, vol. 131, no. 2, pp. 242-247, 2010.

[96] X. Zhang, Y. Song, Y. Wu et al., "Indirubin inhibits tumor growth by antitumor angiogenesis via blocking VEGFR2mediated JAK/STAT3 signaling in endothelial cell," International Journal of Cancer, vol. 129, no. 10, pp. 2502-2511, 2011.

[97] J. K. Kim, E. K. Shin, Y. H. Kang, and J. H. Y. Park, "Indirubin$3^{\prime}$-monoxime, a derivative of a chinese antileukemia medicine, inhibits angiogenesis," Journal of Cellular Biochemistry, vol. 112, no. 5, pp. 1384-1391, 2011.

[98] E. K. Shin and J. K. Kim, "Indirubin derivative E804 inhibits angiogenesis," BMC Cancer, vol. 12, article 164, 2012.

[99] Y. K. Chan, H. H. Kwok, L. S. Chan et al., "An indirubin derivative, E804, exhibits potent angiosuppressive activity," Biochemical Pharmacology, vol. 83, no. 5, pp. 598-607, 2012.

[100] R. Hoffmann and G. S. Mintz, "Coronary in-stent restenosispredictors, treatment and prevention," European Heart Journal, vol. 21, no. 21, pp. 1739-1749, 2000.

[101] V. Farooq, B. D. Gogas, and P. W. Serruys, "Restenosis: delineating the numerous causes of drug-eluting stent restenosis," Circulation: Cardiovascular Interventions, vol. 4, no. 2, pp. 195205, 2011.

[102] A. V. Schwaiberger, E. H. Heiss, M. Cabaravdic et al., "Indirubin-3'-monoxime blocks vascular smooth muscle cell proliferation by inhibition of signal transducer and activator of transcription 3 signaling and reduces neointima formation in vivo," Arteriosclerosis, Thrombosis, and Vascular Biology, vol. 30, no. 12, pp. 2475-2481, 2010.

[103] T. Blažević, A. M. Schaible, K. Weinhäupl et al., "Indirubin$3^{\prime}$-monoxime exerts a dual mode of inhibition towards leukotriene-mediated vascular smooth muscle cell migration," Cardiovascular Research, vol. 101, no. 3, pp. 522-532, 2014.

[104] J. J. Lee, J. H. Han, S. H. Jung et al., "Antiplatelet action of indirubin- $3^{\prime}$-monoxime through suppression of glycoprotein VI-mediated signal transduction: a possible role for ERK signaling in platelets," Vascular Pharmacology, vol. 63, no. 3, pp. 182-192, 2014.

[105] E. Christophers, "Psoriasis-epidemiology and clinical spectrum," Clinical and Experimental Dermatology, vol. 26, no. 4, pp. 314-320, 2001.

[106] M. A. Lowes, A. M. Bowcock, and J. G. Krueger, "Pathogenesis and therapy of psoriasis," Nature, vol. 445, no. 7130, pp. 866-873, 2007.

[107] F. O. Nestle, D. H. Kaplan, and J. Barker, "Psoriasis," The New England Journal of Medicine, vol. 361, no. 5, pp. 444-509, 2009.

[108] Y. K. Lin, Y. L. Leu, S. H. Yang, H. W. Chen, C. T. Wang, and J. H. S. Pang, "Anti-psoriatic effects of indigo naturalis on the proliferation and differentiation of keratinocytes with indirubin as the active component," Journal of Dermatological Science, vol. 54, no. 3, pp. 168-174, 2009.

[109] W. L. Hsieh, Y. K. Lin, C. N. Tsai, T. M. Wang, T. Y. Chen, and J. H. S. Pang, "Indirubin, an acting component of indigo naturalis, inhibits EGFR activation and EGF-induced CDC25B gene expression in epidermal keratinocytes," Journal of Dermatological Science, vol. 67, no. 2, pp. 140-146, 2012.

[110] Y. K. Lin, H. W. Chen, Y. L. Leu, Y. L. Yang, Y. Fang, and T. L. Hwang, "Indigo naturalis upregulates claudin-1 expression in human keratinocytes and psoriatic lesions," Journal of Ethnopharmacology, vol. 145, no. 2, pp. 614-620, 2013.

[111] P. Khanal, H. K. Choi, G. M. Namgoong et al., " 5 '-nitroindirubinoxime inhibits epidermal growth factor- and phorbol ester-induced AP-1 activity and cell transformation through inhibition of phosphorylation of Pin1," Molecular Carcinogenesis, vol. 50, no. 12, pp. 961-971, 2011.

[112] Y. K. Lin, L. C. See, Y. H. Huang et al., "Comparison of refined and crude indigo naturalis ointment in treating psoriasis: randomized, observer-blind, controlled, intrapatient trial," Archives of Dermatology, vol. 148, no. 3, pp. 397-400, 2012.

[113] Y. K. Lin, L. C. See, Y. H. Huang et al., "Efficacy and safety of Indigo naturalis extract in oil (Lindioil) in treating nail psoriasis: a randomized, observer-blind, vehicle-controlled trial," Phytomedicine, vol. 21, no. 7, pp. 1015-1020, 2014. 


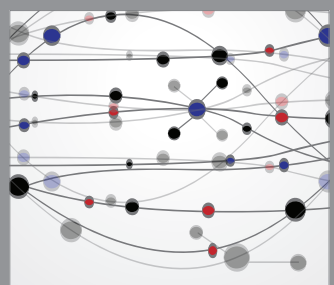

The Scientific World Journal
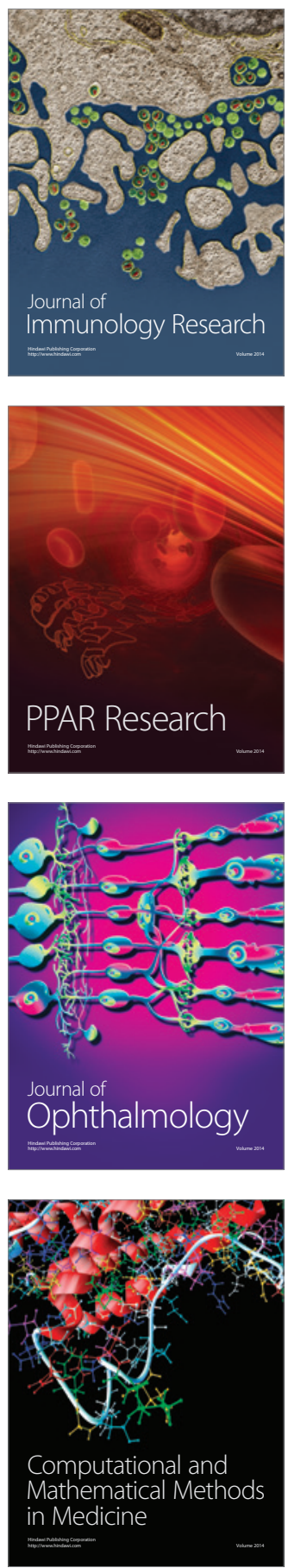

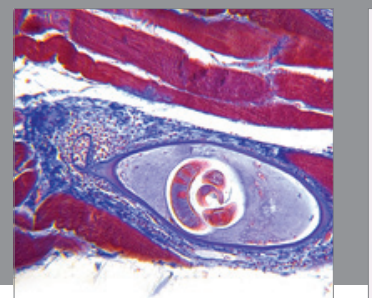

Gastroenterology

Research and Practice
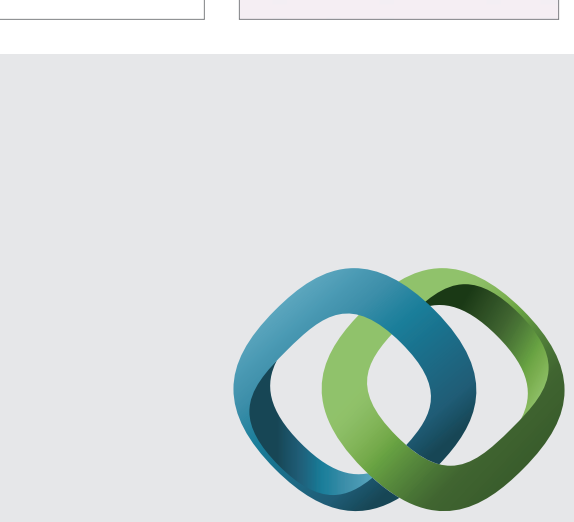

\section{Hindawi}

Submit your manuscripts at

http://www.hindawi.com
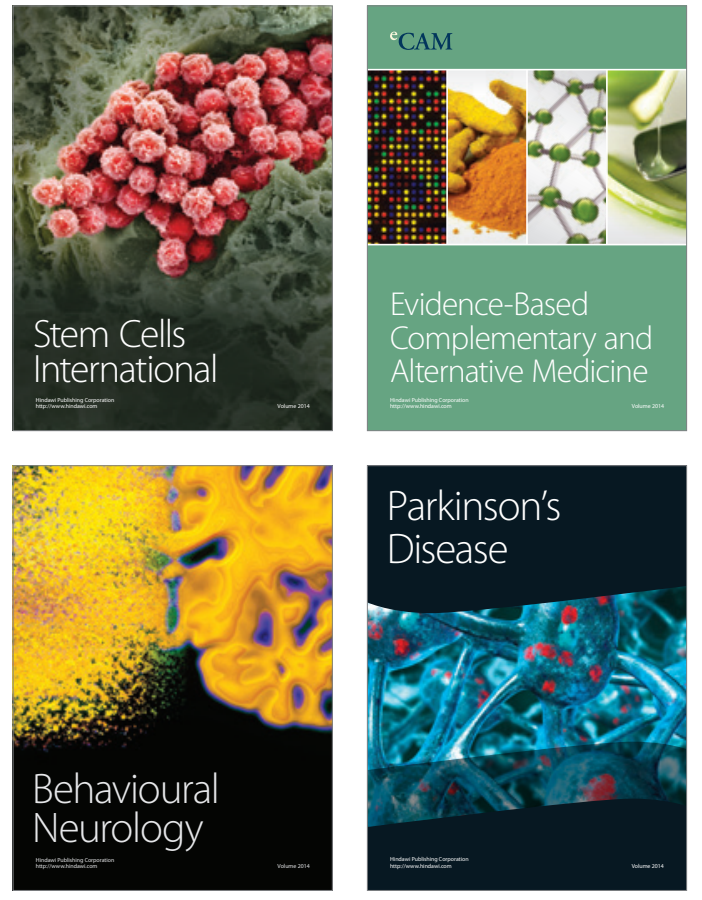
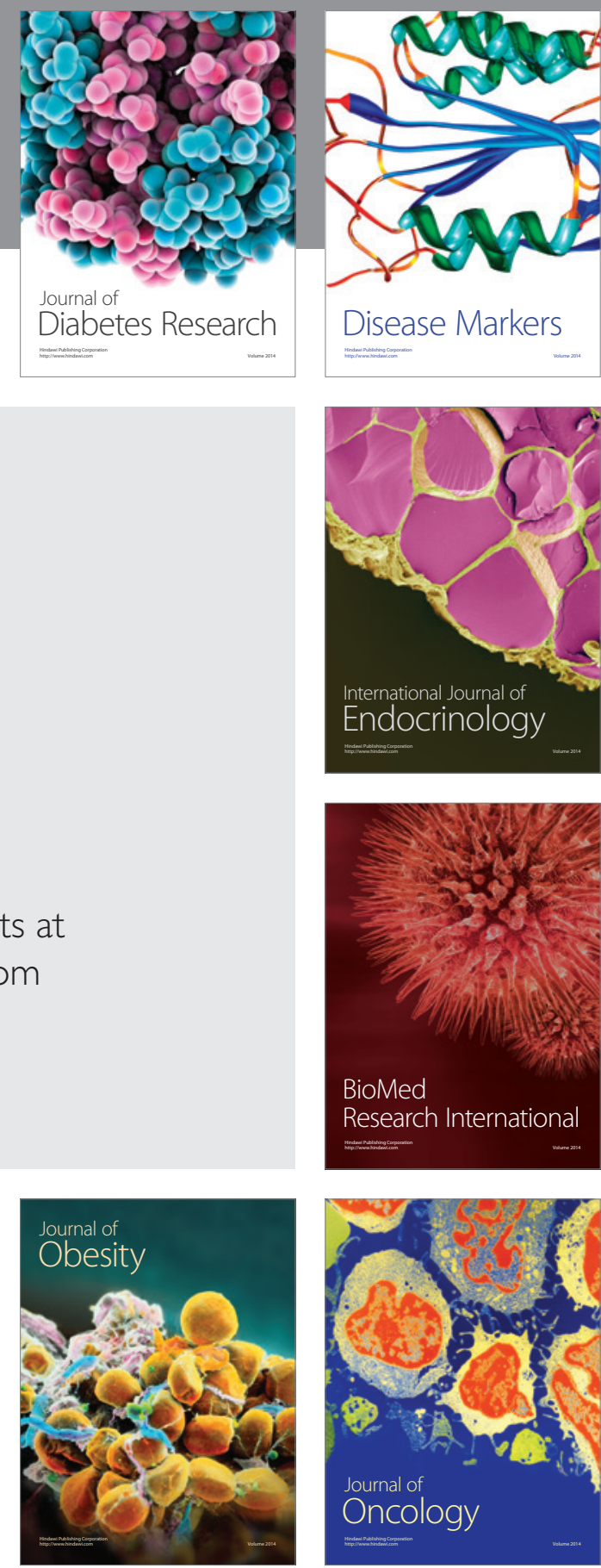

Disease Markers
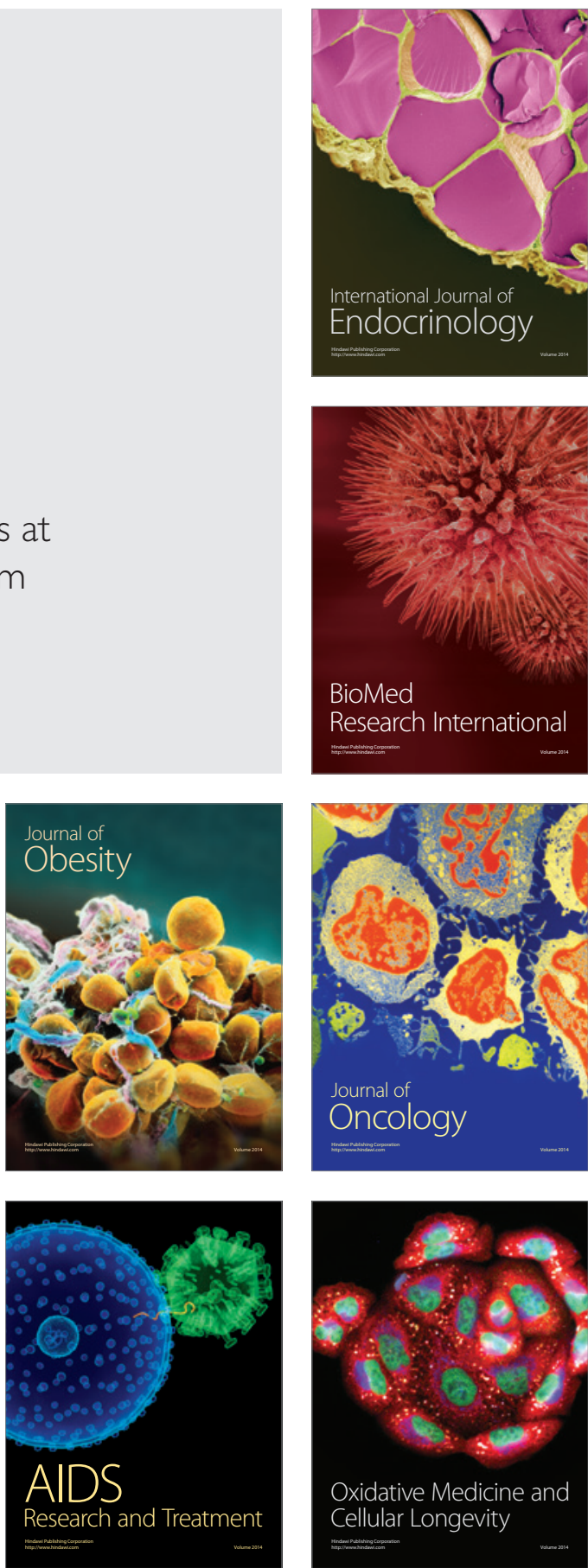